\title{
PENINGKATAN KESADARAN AKAN PENGELOLAAN SAMPAH DI DESA CINTA MULYA MELALUI WORKSHOP INTEGRATIF DAN KREATIF
}

\author{
Ivan Darmawan, Muhammad Dhiyaul Haq, dan Philia Anindita Ginting \\ Fakultas Ilmu Sosial dan Ilmu Politik, Universitas Padjadjaran \\ E-mail: ivan.idevice@gmail.com
}

\begin{abstract}
ABSTRAK. Desa Cinta Mulya terletak di Kawasan Pendidikan Jatinangor, Kabupaten Sumedang. Peningkatan jumlah penduduk yang signifikan di Kecamatan Jatinangor secara tidak langsung membawa dampak kepada lingkungan Desa Cinta Mulya. Salah satu permasalahan yang dihadapi di lingkungan Desa Cinta Mulya adalah pengelolaan sampah yang belum memadai. Tidak adanya Tempat Pembuangan Akhir serta pengetahuan masyarakat akan pengelolaan sampah yang minim, menyebabkan lingkungan menjadi kotor dan tercemar. Maka dari itu, perlu adanya kegiatan untuk meningkatkan kesadaran warga akan pengelolaan sampah dan kebersihan lingkungan. Metode yang digunakan pada kegiatan ini merupakan metode Participatory Rural Appraisal, kemudian ditunjang dengan kegiatan workshop selama dua hari yang ditujukan bagi warga Desa Cinta Mulya terkhusus kaum ibu, karang taruna dan anak-anak. Kegiatan ini juga melibatkan core group atau tokoh masyarakat yang diharapkan dapat menyebarluaskan pengetahuan yang telah didapat. Kegiatan dengan anak-anak dilakukan dengan menarik, melalui pembuatan kreasi tempat sampah serta pemaparan materi mengenai sampah organik dan non-organik. Hasil dari kegiatan ini didapatkan bahwa terdapat peningkatan pengetahuan dan kepedulian masyarakat mengenai pengelolaan sampah serta kebersihan lingkungan.
\end{abstract}

Kata Kunci: Integratif; Kreatif; Pengelolaan Sampah; Workshop.

ABSTRACT. Cinta Mulya Village is located in the Jatinangor Education Area, Sumedang Regency. The significant increase in population in Jatinangor District has indirectly had an impact on the environment of Cinta Mulya Village. One of the problems faced in Cinta Mulya Village is inadequate waste management. The absence of a landfill and minimal knowledge of the community about waste management, causing the environment to become dirty and polluted. Therefore, there is a need for activities to increase citizen a wareness of waste management and environmental cleanliness. The method used in this activity was the Participatory Rural Appraisal method, which was then supported by a two-day workshop aimed at residents of Cinta Mulya Village, especially mothers, youth organizations and children. This activity also involves a core group or community leaders who are expected to spread the knowledge that has been obtained. Activities with the children were carried out in an interesting manner, through the creation of trash cans and the presentation of material on organic and non-organic waste. The results of this activity show that there is an increase in knowledge and awareness of the community regarding waste management and environmental hygiene.

Keyword: Integrative; Creative; Waste Management; Workshop.

\section{PENDAHULUAN}

Desa Cinta Mulya adalah salah satu desa yang berada di Kecamatan Jatinangor Kabupaten Sumedang. Berdasarkan sumber data, secara administratif Desa Cinta Mulya terbagi kedalam 4 dusun yakni, Dusun I, Dusung II Citanggulun, Dusun III Cibungur dan Dusun IV Cipajaran. Desa Cinta Mulya terdiri dari 8 RW dan 31 RT. Luas wilayah Desa Cinta Mulya adalah sebesar 144 ha yang didominasi oleh bangunan gedung pabrik. Hanya sebagian kecil saja yang menjadi rumah penduduk dan lahan pertanian. Dengan demikian, Desa Cinta Mulya juga menjadi kawasan industri yang diisi beberapa pabrik besar seperti PT Kahatex. Sehingga sebagian besar penduduknya bekerja sebagai pekerja pabrik.

Salah satu permasalahan yang dihadapi oleh masyarakat Desa Cinta Mulya adalah pengelolaan sampah. Permasalahan pengelolaan sampah di Desa Cinta Mulya dikarenakan sampah rumah tangga yang menumpuk belum terkelola dengan baik, hal ini disebabkan oleh belum tersedianya Tempat Pembuangan Akhir (TPA) maupun petugas kebersihan yang bertugas mengkolektifkan sampah. Selain itu, tidak ditemukan adanya tempat sampah umum untuk menampung sampah sementara, sehingga cara yang dilakukan warga untuk menangani sampah yang menumpuk adalah dengan dibakar. Kesadaran masyarakat akan kebersihan dan pengelolaan sampah juga masih minim, hal ini dapat dilihat dari perilaku warga yang kerap membuang sampah di sungai, di pinggir jalan, dan dimana saja.

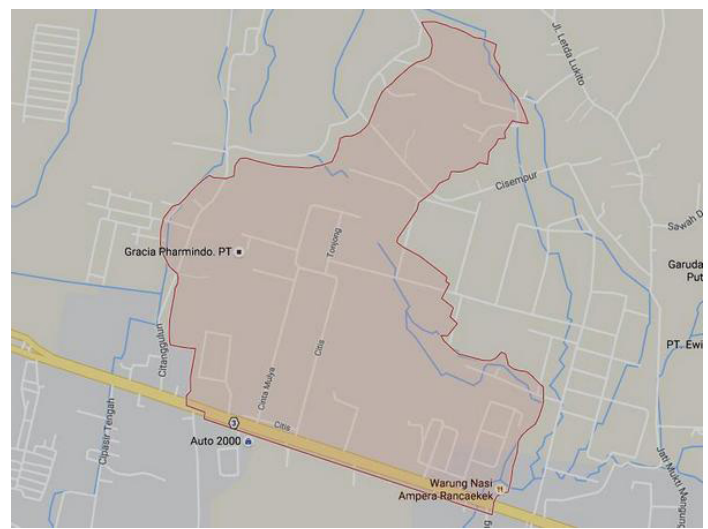

Gambar 1. Peta Wilayah Desa Cintamulya

Sumber: sumedangtandang.com, 2019. 
Dikutip dari Jabar Ekspres, bertambah padatnya penduduk di wilayah Jatinangor juga mengakibatkan meningkatnya produksi sampah. Banyaknya sampah rumah tangga yang dibuang tiap hari mencapai berat enam ton sampah. Salah satu pengurus Komunitas Peduli Sampah Desa Cinta Mulya, Uken, menambahkan bahwa di Desa Cinta Mulya sendiri memproduksi sampah kurang lebih dua ton per harinya. Keaadan ini bertambah buruk apabila hujan datang, tidak jarang wilayah Jatinangor termasuk Desa Cinta Mulya ikut terkena dampak banjir yang disertai sampah-sampah yang terbawa arus. Kemudian, Usup melalui detik menyatakan bahwa walaupun sebelumnya Desa Cinta Mulya telah memiliki saluran air sendiri, saat saluran air disatukan akhirnya sampah dari wilayah lain ikut terseret air hujan sehingga menumpuk ke tanah dan menyumbat lalu lintas air melalui gorong-gorong (Putra, 2017).

Sampah jelas sudah menjadi salah satu permasalahan yang dihadapi oleh masyarakat dan pemerintah di Desa Cinta Mulya. Menurut Nugroho (2013) sampah merupakan barang yang dianggap sudah tidak terpakai dan dibuang oleh pemilik atau pemakai sebelumnya, tetapi bagi sebagian orang masih dapat dipakai jika dikelola dengan prosedur yang benar. Lebih lanjut Nugroho mengelompokkan sampah berdasarkan sumber, sifat, dan bentuk. Sampah berdasarkan sumbernya dikelompokkan menjadi sampah alam, sampah manusia, sampah konsumsi, sampah nuklir, sampah industri, dan sampah pertambangan. Adapun berdasarkan sifatnya sampah dikelompokkan menjadi sampah organik dan anorganik. Sedangkan, berdasarkan bentuknya sampah digolongkan menjadi sampah padat dan sampah cair.

Pada hakikatnya sampah adalah material sisa yang tidak diinginkan namun ada pula sampah organik yang dapat diuraikan (degredable) maupun sampah anorganik (undegradable) yang memiliki masa tersendiri untuk dapat diuraikan. Apabila tidak dipisahkan untuk diolah kembali di tempat pembuangan akhir, permasalahan ini dapat menimbulkan dampak seperti pencemaran air, udara, tanah hingga sumber penyakit. Dengan demikian, secara khusus artikel ini akan memaparkan kegiatan workshop ini meletakkan fokusnya pada pengelolaan sampah dengan workshop integratif dan kreatif.

\section{METODE}

Metode yang digunakan pada kegiatan ini adalah menggunakan metode Participatory Rural Appraisal (PRA). Metode PRA adalah metode pendekatan yang memungkinkan masyarakat untuk saling berbagi, meningkatkan, dan menganalisis pengetahuan mereka tentang kondisi dan permasalahan, serta membuat rencana dan bertindak (Chambers, 1996). Penggunaan metode PRA bertujuan untuk menghasilkan rancangan program yang gayut dengan hasrat dan keadaan masyarakat, selain itu juga bertujuan untuk mengembangkan kemampuan masyarakat dalam menganalisa keadaan dan melakukan perencanaan melalui kegiatan.

Pengelolaan sampah di Desa Cinta Mulya dilakukan selama dua hari dengan sasaran objek ibuibu, karang taruna dan Anak-Anak. Beberapa langkah yang dilakukan dalam program peningkatakan kesadaran masyarakat ini dilakukan dalam beberapa tahap sebagai berikut:

1. Survey Lapangan dan Pemetaan

Survey lapangan dilakukan bersama dengan salah satu ibu PKK di Desa Cinta Mulya. Kegiatan berupa pengamatan terhadap kondisi desa yang dilanjutkan dengan pemetaan lokasi-lokasi yang banyak ditemukan sampah menumpuk di Desa Cinta Mulya.

2. Berkoordinasi dengan Tokoh Masyarakat dan Mengurus Perizinan

Berkoordinasi dengan Kepala Desa Cinta Mulya untuk mengadakan workshop serta mengundang beberapa tokoh masyarakat yang hendak dijadikan sebagai core group. Core group merupakan kelompok inti yang nantinya diharapkan dapat mengkoordinasikan dan melanjutkan pembelajaran dan kegiatan kepada warga Desa Cinta Mulya. Beberapa core group yang hadir yakni: 12 orang dari perangkat desa, 2 orang dari perwakilan kader, 2 orang dari BPD, 2 orang dari LPM, 10 orang RW, 2 orang Karang Taruna, 1 orang Danton (komandan peleton), dan 2 orang Babinsa (Bintara Pembina Desa).

Kegiatan yang dilakukan selama dua hari yang dilakukan di kantor kepala desa dan 3 Sekolah Dasar yang ada di Desa Cinta Mulya yakni SD Paripurna, SD Mekarwangi, dan SD MI. Selanjutnya, membuat surat undangan yang disebarkan kepada tokoh masyarakat untuk menghadiri kegiatan workshop.

3. Kegiatan Workshop dan Evaluasi Kegiatan Kegiatan workshop pengelolaan sampah dibagi dua objek sasaran yakni kepada ibu-ibu dan anakanak. Workshop ibu-ibu bersama Karang Taruna dilakukan dengan kegiatan pemaparan materi serta sesi tanya jawab sedangkan kegiatan di SD dilakukan dengan membuat dan menghias tempat sampah serta pembelajaran interaktif. Kedua kegiatan ini didukung oleh DLH Jabar.

Evaluasi kegiatan dilakukan secara mandiri oleh kelompok mahasiswa seusai kegiatan workshop. Selanjutnya dilakukan dengan memberikan presentasi kepada Kepala Desa dan berbagai 
tokoh masyarakat berisikan kegiatan $\mathrm{KKN}$, hasil, dan evaluasi yang dilakukan.

\section{HASIL DAN PEMBAHASAN}

Sampah tidak akan menjadi permasalahan apabila terkelola dengan benar. Namun, seiring dengan perkembangan zaman dan penambahan jumlah penduduk ternyata persoalan sampah semakin menjadi permasalahan serius yang harus dihadapi oleh masyarakat. Pada umumnya, pengelolaan sampah di Indonesia dilaksanakan secara terpadu yang langsung disalurkan menuju Tempat Penampungan Sementara (TPS) tanpa melalui proses pemilahan dan pengelolahan. Tahap selanjutnya akan diangkut menuju Tempat Pembuangan Akhir (TPA) yang kemudian ditimbun. Solusi seperti ini tidak menyelesaikan masalah dan mengabaikan nilai sampah sebagai sumber daya.

Persoalan ini pula yang dihadapi oleh masyarakat di Desa Cinta Mulya. Guna memperoleh informasi yang faktual, mahasiswa melakukan assesment berupa pengumpulan data melalui wawancara dan survey bersama tokoh masyarakat. Wawancara ini dilakukan pertama kali bersama dengan Kepala Desa. Hasil wawancara menunjuukan data bahwa salah satu penyebab pengelolaan sampah di Desa Cinta Mulya tidak terkendaliadalah karena tidak tersedianya TPS dan TPA serta petugas kebersihan yang bertugas mengkolektifkan sampah. Pada akhirnya, satu-satunya cara pengolahan sampah yang dilakukan masyarakat adalah dengan cara pembakaran.

Selanjutnya dalam kegiatan survey dilakukan dengan penyusuran desa bersama dengan tokoh masyarakat. Dari hasil survey ditemukan bahwa hampir disetiap lokasi tempat umum seperti sekolah, warung, tempat makan, pasar, danau, dll ditemukan sampah berserakan. Selama kegiatan survey tidak ditemukan tempat sampah umum maupun TPS sehingga semua sampah itu tertumpuk pada sungai yang sudah mengering. Dampak yang terasa langsung adalah timbulnya bau yang tidak sedap, pemandangan terganggu serta perasaan tidak nyaman menyusuri tempat yang terdapat banyak sampah.

Dari hasil assesment tersebut maka dapat diketahui bahwa pengelolaan sampah di Desa Cinta Mulya membutuhkan perhatian khusus. Selain itu, hal ini tidak sesuai dengan perancangan sistem pengelolaan sampah rumah tangga yang megacu kepada Peraturan Menteri Pekerjaan Umum No 21 Tahun 2006 tentang kebijakan dan strategi nasional pengembangan sistem pengelolaan persampahan dan teknis tata kelola. Secara garis besar kebijakan ini mengacu kepada pendekatan 3R yakni reduce, reuse, recycle yakni penanganan sampah dengan cara dikurangi, digunakan kembali, dan didaur ulang. Dari data primer dibenarkan bahwa pernah berjalan program Bank Sampah di Desa Cinta Mulya namun program ini terhenti dan tidak menjadi berkelanjutan.

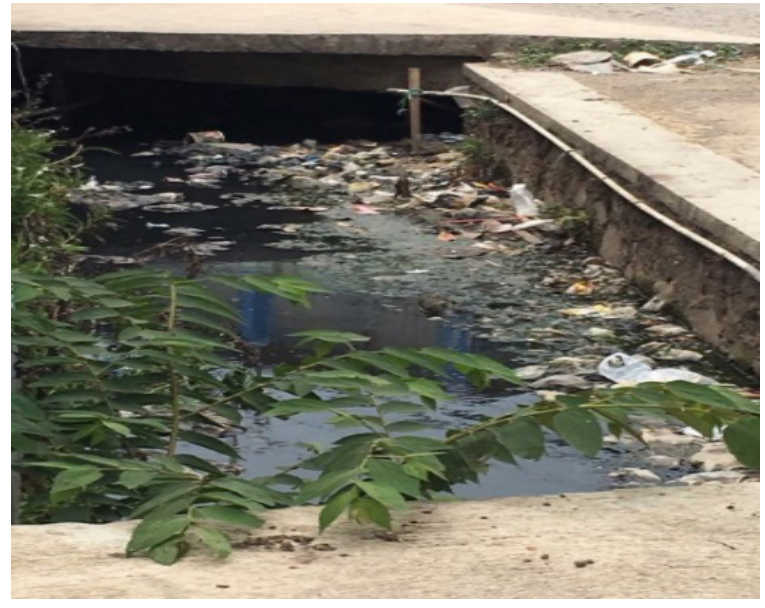

Gambar 2. Foto sampah di parit sebelah pabrik Sumber: diambil oleh peneliti, 2019.

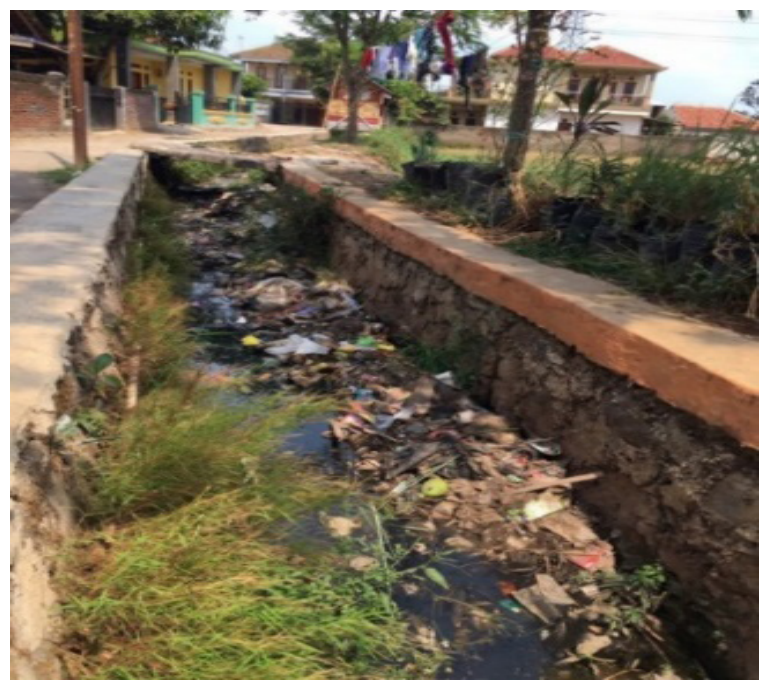

Gambar 3. Foto sampah di salah satu parit yang disusuri

Sumber: diambil oleh peneliti, 2019.

\section{Workshop Bersama Ibu-Ibu}

Kegiatan ini diberikan secara khusus kepada ibu-ibu mengingat kebanyakan sampah berasal dari sampah rumah tangga. Berdasarkan hasil survey sering ditemukan sampah rumah tangga berupa sampah organik yang menumpuk didepan rumah maupun di selokan yang menimbulkan bau tak sedap. Menurut Pervez Alam dan Kafeel Ahmad (2013), penumpukan sampah dapat menyebabkan masalah yang mampu menimbulkan masalah lain seperti polusi air, tanah dan udara.

Upaya pengelolaan sampah tidak saja menjadi tanggung jawab penuh pemerintah namun perlu dilakukan bersama-sama dengan pihak swasta dan masyarakat karena tidak dapat dipungkiri makhluk hidup sangat bergantung dengan alam, kita perlu melestarikan dan membuat bumi menjadi tempatyang 
layak untuk ditinggali. Melalui pemaparan materi yang disampaikan, diharapkan akan meningkatkan kesadaran (awareness) serta sebagai ajakan untuk turut berpikir mencari solusi bagi permasalahan pengelolaan sampah tersebut. Disamping itu, dalam workshop ini juga dipaparkan dampak sampah dari segi kesehatan seperti sumber penyakit ISPA, DBD, dan diare. Sumber-sumber sampah juga tidak hanya berasal dari pemukiman namun dapat berasal dari pertanian, perkebunan, hasil konstruksi bangunan, hasil berdagang hingga industri.

Guna meningkatkan kesadaran ibu-ibu akan pengelolaan sampah maka dalam kegiatan workshop menawarkan 5R yakni reduce, reuse, recycle, replace, dan repair. Reduce berarti mengurangi sampah yang dihasilkan dengan pengurahan bahanbahan ayng dapat merusak lingkungan. Reuse adalah penggunaan kembali barang-barang yang dirombak atau dimodifikasi ulang menjadi bentuk baru. Recycle adalah kegiatan emndaur ulang barang . Replace adalah untuk menghindari atau mengganti barang sekali pakai menjadi barang yang dapat digunakan berulang-ulang. Terakhir, repair yakni dengan memperbaiki barang-barang yang rusak agar bisa dipakai kembali. Terakhir, pemaparan yang diberikan adalah tentang sampah organik dan anorganik.

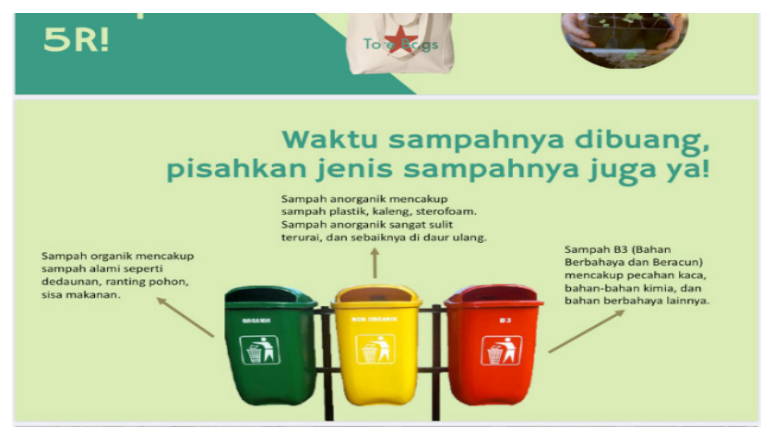

Gambar 4. Pemaparan sampah organik dan nonorganik

Sumber: hasil olahan peneliti, 2019.

\section{Workshop Tempat Sampah Kreatif}

Kegiatan selanjutnya dilaksanakan di 3 SD yang dilaksanakan dalam waktu yang bersamaan. Metode yang dipilih oleh kami dalam melakukan pendekatan anak-anak adalah melalui permainan. Peningkatan awareness akan pengelolaan sampah kepada anak-anak melalui game "Peta Waktu". Game ini memaparkan berbagai sampah organik dan organik dengan masa lama terurainya. Dari game ini diharapkan anak mengetahui bahwa untuk mengelola sampah dibutuhkan waktu dan proses yang cukup lama sehingga diperlukan pengetahuan lebih lanjut.

Kegiatan dilanjutkan dengan membuat dan menghias tempat sampah yang sudah disediakan oleh mahasiswa. Tempat sampah ini dihias dan dipersembahkan bagi setiap kelas. Seusai pembuatan tempat sampah ini dilanjutkan dengan kegiatan bersih-bersih kelas bersama dengan memanfaatkan tempat sampah yang telah dibuat.

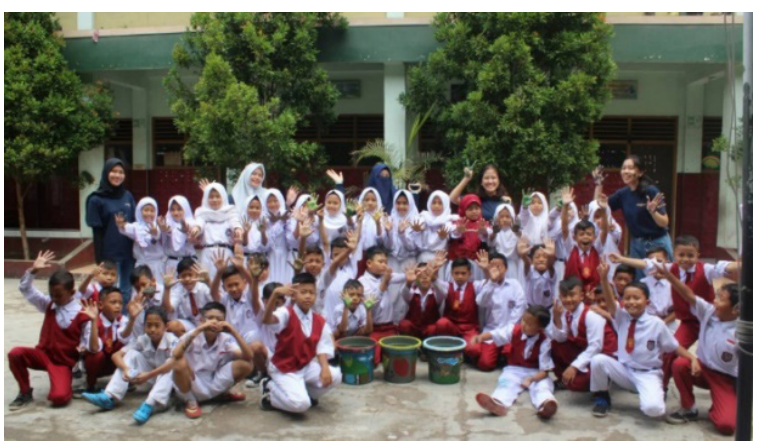

Gambar 5. Siswa SD Paripurna

Sumber: diambil oleh peneliti, 2019.

\section{SIMPULAN}

Dari kegiatan KKN mengenai topik pengelolaan sampah ini ditemukan bahwa masih sangat kurang pengelolaan sampah di Desa Cinta Mulya. Pengetahuan masyarakat serta kewajiban aparat pemerintah akan pengelolaan sampah juga memerlukan perhatian karena melihat belum terdapatnya tempat sampah umum, TPA, maupun petugas yang menjaga kebersihan umum. Tidak hanya pemerintah namun juga dibutuhkan kesadaran dari warga dalam persoalan sampah. Dari hasil kegiatan workshop yang diberikan kepada ibu-ibu serta anak-anak menunjukkan adanya peningkatan pemahaman mengenai pentingnya mengelola sampah dan menjaga kebersihan lingkungan. Sehingga diharapkan dengan integrasi yang baik diantara core group dan masyarakat Desa Cinta Mulya permasalahan dan pengelolaan sampah dapat ditangani dengan baik.

\section{DAFTAR PUSTAKA}

Chambers, R. 1996. Participatory Rural Appraisal: Memahami Desa Secara Partisipatif. Yogyakarta: Kanisius.

Nugroho, Panji. 2013. Panduan Membuat Kompos Cair. Jakarta: Pustaka baru Press.

Alam, Pervez \& Kafeel Ahmade. 2013. Impact of Solid Waste On Health and The Environment. Menurut Pervez Alam dan Kafeel Ahmade. (2)1. 165-168.

Fordian, D. 2017. Penyuluhan Metode Pembuangan Sampah Organik dan Sampah Non Organik. Dharmakarya - Jurnal Aplikasi Ipteks Untuk Masyarkat, 129-135.

Hidayat, M. A. 2015. Rancang Bangun Mesin Pencacah Sampah Organik (Perawatan Dan Perbaikan). Thesis, Politeknik Negeri Sriwijaya., 5-13. 
Ismail, M. R. 2017. Peduli Lingkungan RW 05 Desa Cisempur Melalui Pengelolaan Sampah. Dharmakarya Jurnal Aplikasi Ipteks untuk Masyarakat, 224-226.

Malik, A. 2016. Desa Cinta Mulya. Retrieved from Sumedang Tandang. (http:// sumedangtandang.com/direktori/detail/desacinta-mulya.html, diakses 19 November 2019)

Nurman, Iman. 2018. Volume Sampah di Jatinangor Tinggi. Retrieved from Jabar Ekspres. (http:// jabarekspres.com/2018/volume-sampahdi-jatinangor-tinggi/, diakses 17 November 2019)
Putra, W. 2017. Warga Sumedang Keruk Tumpukan Sampah Penyebab Banjir. Retrieved from Detik.com. (https://news.detik.com/beritajawa-barat/d-3766954/warga-sumedangkeruk-tumpukan-sampah-penyebab-banjir, diakses 18 November 2019).

Peraturan Menteri Pekerjaan Umum No 21 Tahun 2006 Tentang Kebijakan dan Strategi Nasional Pengembangan Sistem Pengelolaan Persampahan 